\section{UMA PROPOSTA DE IMPLANTAÇÃO DE COLETA SELETIVA NO CONDOMÍ- NIO RECANTO VERDE, ARACAJU/SE}

Mayane Menezes Santos

Ângelo Francklin Pitanga

\title{
Resumo:
}

A Educação Ambiental torna-se relevante por enfocar e colocar em discussão questões políticas, econômicas e sociais, as quais fazem parte da vida dos seres humanos em sua relação com a natureza, abraçando a ideia de sustentabilidade, diante de uma cultura de consumo desenfreada, praticada especialmente pelas populações residentes nas áreas urbanas. Esse trabalho propõe o processo de implantação da coleta seletiva no Condomínio Residencial Recanto Verde, localizado no bairro Farolândia, na zona sul de Aracaju, com o objetivo de promover à educação ambiental e proporcionar uma melhor destinação e separação dos resíduos produzidos nessa área. As ações do projeto foram desenvolvidas através de questionários, aplicados com o intuito de analisar o entendimento dos moradores sobre coleta seletiva e sua devida implantação, além da sua relação com o consumo. Apesar da falta de recurso para isso, é importante destacar o interesse dos condôminos e funcionários na implantação dessa proposta.

Palavras-chave: Educação Ambiental. Consumo. Coleta seletiva

\section{A PROPOSAL FOR THE IMPLEMEN- TATION OF SELECTIVE WASTE COL- LECTION IN CONDOMÍNIO RECANTO VERDE , ARACAJU / SE}

\begin{abstract}
:
The Environmental Education become relevant by focusing and putting in discussion political, economical and social questions, which are part of human beings' life in their relationship with nature, embracing the idea of sustainability, in front of a rampant consumption's culture, practiced especially by the urban resident populations. This work propose the implantation process of the waste collection at the Condomínio Residencial Recanto Verde, located in the Farolândia district, in Aracaju's South Area, to promote the environmental education and to provide a better destination and separation of the waste produced in this area. The project's actions were developed through questionnaires, applied with the intent of to analyze the residents' understanding about the waste collection and its implantation, in addition to its relation with the consumption. Despite the lack of resource for this, is important to highlight the condominium members and workers' interest in the implantation of this proposal.
\end{abstract}

Keywords: Environmental Education. Consumption. Waste Collection 


\section{UNA PROPUESTA DE IMPLANTACIÓN DE COLECTA SELECTIVA EN EL CON- DOMINIO RECANTO VERDE, ARACAJU / SE}

\section{Introdução}

A noção de sustentabilidade corresponde não apenas ao desenvolvimento econômico e material de uma determinada região do planeta, mas, principalmente, a uma conduta especial do ser humano capaz de possibilitar o compartilhamento da vida em sociedade e de evitar as possibilidades de agressão ao meio ambiente.

Esta conduta exige redefinir as ações humanas no sentido de suprir as nossas necessidades de sobrevivência, criando ao mesmo tempo uma relação harmônica de troca com os meios naturais, a cada dia mais devassado pelo processo de expansão dos centros urbanos. Portanto, carecemos refletir sobre questões como economias de recursos: reciclar, diminuir resíduos e saber utilizar melhor os bens que consumimos.

Segundo Portilho (2005), a partir da década de 1980 vem se estabelecendo uma nova percepção social sobre o impacto ambiental do consumo, o que provocao surgimento de uma nova compreensão sobre o problema da crise ambiental. Novas definições e novas estratégias têm sido desenvolvidas no sentido de estimular e divulgar uma consciência crítica sobre a problemática ambiental, a qual requer uma mudança de comportamento nas nossas formas de consumo.

Um dos pontos importantes a serem discutidos e avaliados é a quantidade de lixo gerada cotidianamente nas residências. Atualmente, a implantação de cooperativas de reciclagens em algumas localidades tem possibilitado melhorar a triagem, seleção, prensagem e comercialização dos resíduos coletados. A ideia vigente é que o processo de reciclagem deve ser iniciado nas residências e nos condomínios, a exemplo do que se pretende enfocar nesta pesquisa.

Segundo informações recolhidas pelo Ministério Público do Estado de Sergipe, em 29 de agosto de 2016, a Secretaria do Meio Ambiente, com o envolvimento da Cooperativa dos Agentes Autônomos de Reciclagem de Aracaju (CARE), instituíram o Projeto Lixo e Cidadania em Sergipe, coordenado pelo Ministério Público do Estado, com o intuito de implantar a educação ambiental e gerar a inclusão social dos catadores de lixo, através do eixo da Geração de Emprego e Renda (SERGIPE, 2016). 
Atualmente, a cooperativa recicla cerca de 60 toneladas por mês de material recolhido e descartado, proveniente de diversos bairros e conjuntos residenciais de Aracaju, nos quais a Empresa $\mathrm{Mu}-$ nicipal de Serviços Urbanos (EMSURB) implantou o sistema de coleta seletiva. São utilizados nessas operações 45 associados e, segundo dados apresentados pelo site da Prefeitura Municipal de Aracaju, de 22 de janeiro de 2013:

A construção de uma unidade produtiva para o beneficiamento e comercialização de material reciclável, em condiçõ̃es mais dignas de trabalho (fora da catação de resíduos em lixeiras a céu aberto), proporciona a melhoria no nível de renda das famílias que desenvolviam essas atividades na Lixeira da Terra Dura (ARACAJU, 2013, s/n).

Do ponto de vista da importância social, a cooperativa funciona como uma ancoragem de sobrevivência para dezenas de famílias que não possuem vínculo empregatício, dificuldade gerada, entre outras questões, pela impossibilidade de se inserir no mercado de trabalho pela via da qualificação profissional.

O trabalho dos recicladores, além de ajudar na preservação da natureza e no equilíbrio do meio ambiente, possibilita renda e ocupação para dezenas de pessoas que não possuem vínculo empregatício. Nesse viés, a cooperativa é uma alternativa importante que destaca procedimentos mais criativos para o reaproveitamento dos resíduos, com uma proposta de inclusão social e ambiental, viabiliza uma forma de consumo sustentável em áreas urbanas de Aracaju/SE.

De acordo com a publicação em site da Prefeitura Municipal de Aracaju (2013), mais de três mil toneladas de resíduos inorgânicos que levariam dezenas ou centenas de anos para se decompor, deixaram de ser levados ao Lixão do Santa Maria. A média mensal era de 240 toneladas de material recolhido pela equipe de 17 trabalhadores, entre motoristas, fiscais e agentes transportados nos cinco caminhões coletores do programa (ARACAJU, 2013).

Esses trabalhadores percorrem a cidade em diferentes dias e horários da coleta de lixo comum, seguindo itinerário próprio. A diferenciação de rota proporciona maior comodidade e segurança à população, que pode realizar o descarte próximo à residência com a certeza de que o material separado com tanta dedicação será realmente aproveitado e reciclado.

Contudo, percebemos que com a separação realizada da forma correta, reduz-se a mistura do resíduo orgânico ou úmido (restos de comida, guardanapos, papel higiênico etc.) e do resíduo inorgânico ou seco (embalagens plásticas, garrafas pet, canos e tubos, garrafas e frascos de vidro em geral, copos, potes de produtos alimentícios, latas de refrigerante, de leite em pó, de conservas, envelopes, jornais, revistas etc.). Pois, os materiais sólidos e secos que poderiam ser reaproveitados ao entrar em contato com o material úmido são descartados por estarem molhados e sujos.

A problemática desse trabalho está no modo reflexivo como os moradores, síndico e funcionários poderiam reagir à implantação da coleta seletiva nesse condomínio. Nesse sentido, buscou-se harmonizar a disseminação dessa ação socioambiental através da mobilização das pessoas envolvidas nessa área urbana e na verificação de recursos para efetivação da mesma.

Nessa pesquisa propomos uma maneira de incluir a coleta seletiva no Condomínio Recanto Verde, localizado no bairro Farolândia, em Aracaju/SE, com o objetivo de realizar um levantamento do conhecimento prévio e das opiniões dos moradores, sindico e funcionários, sobre esta possível implantação e, consequentemente, proporcionar uma melhor destinação e separação dos resíduos da localidade. Para tanto, foi necessário conquistar a adesão de todos para a realização dessas ações, despertando nos moradores uma nova forma de compreender e conciliar a ideia de consumo com uma conduta mais responsável e proativa em relação à sustentabilidade do Ambiente.

\section{Educação Ambiental, Consumo e Coleta Sele- tiva}

A Lei $n^{\circ}$ 9795/1999, a respeito da Política Nacional de Educação Ambiental, no Art $1^{\circ}$, compreende a Educação ambiental como:

Processos por meio dos quais o indivíduo e a coletividade constroem valores sociais, conhecimentos, habilidades, atitudes e competências voltadas 
para a conservação do meio ambiente, bem de uso comum do povo, essencial a sadia qualidade de vida e sua sustentabilidade (BRASIL, 1999, p. 1).

É de fundamental importância que os cidadãos cumpram com o dever de cuidar bem da nature$\mathrm{za}$, visto que é por meio dela que suprimos nossas necessidades básicas.

A nossa casa comum ${ }^{l}$, o planeta Terra, está enfrentando grandes problemas socioambientais que dependem da forma que nós humanos estamos tratando-a, usufruindo dos recursos naturais. Por essa necessidade constante, precisamos pensar e agir rumo à sustentabilidade. A humanidade deixou de ser o centro prioritário do universo e a natureza está respondendo a agressão sofrida, sendo uma reação à quebra da cadeia harmoniosa do nosso ecossistema.

A Educação Ambiental compreende essa problemática socioambiental e enfatiza o processo individual e coletivo de mudança de comportamento diante da ruptura no funcionamento harmonioso dos ecossistemas. Ao fazermos uma análise das relações políticas, econômicas, sociais e culturais entre os seres humanos e da natureza entre os próprios seres humanos, podemos identificar formas de minimizar os problemas socioambientais.

Nas últimas décadas do século XX e início do século XXI, o debate sobre questões ambientais ganhou destaque no âmbito das políticas públicas, diante dos inúmeros problemas do modelo de desenvolvimento econômico e de produção (Nepomuceno, Carvalho e Rezende, 2014), sendo em destaque um dos grandes problemas ambientais na atualidade que está voltado para o consumo desenfreado da população e a consequente geração de resíduos.

Estima-se em cerca de trinta bilhões de toneladas o total de resíduos sólidos anuais gerados pelos seres humanos (COSTA, 2007). Dessa maneira, a coleta seletiva unicamente não é uma solução para todos os problemas ambientais, pois a destinação final do lixo urbano no Brasil, geralmente, concentra-se em periferias das cidades, locais que não são prioridades na aplicação de recursos

1 Nossa casa comum: termo utilizado pelo eclesiástico Papa Francisco, centrado em questões ambientais, conforme consta no Diário de Coimbra (21-07-2015). por parte da administração municipal.

Então, consideramos que a falta de alternativas adequadas de descartes dos resíduos causam graves problemas de saúde pública, bem como, os desastres ambientais no meio urbano e rural provocados, por exemplo, pelo lixo jogado nos rios e córregos (GRIMBERG, 2004). O lixo ao ser jogado fora, sem os devidos cuidados, contamina pessoas e o ambiente, dificultando o manuseio e o seu aproveitamento.

De acordo com Ferreira (1986, p. 1838), o lixo "é aquilo que se varre de casa, do jardim, da rua e se joga fora; entulho é tudo o que não presta e se joga fora; sujidade, sujeira, imundície são coisas inúteis, sem valor". Os restos alimentares, embalagens descartadas e objetos inservíveis quando misturados são considerados lixos e seu destino será o aterro sanitário. Contudo, quando o material seco do úmido é separado, passamos a ter resíduos recicláveis e o que não tem como ser reaproveitado é chamado de rejeito (GRIMBERG, 2004).

De acordo com Vilhena e D'Almeida (2000), a separação de resíduo orgânico e inorgânico contribui para a redução do volume de lixo a ser disposto em aterros e o aumento de sua vida útil, a redução de gastos públicos com o tratamento e a disposição final do lixo; a redução do consumo de energia e de matérias-primas nos processos industriais; a redução do risco de degradação dos recursos naturais e a proliferação de vetores, fazendo desta alternativa uma grande aliada frente à crescente geração de resíduos.

Tristão (2004) diz que a educação está diretamente relacionada com a produção de sentidos e de valores. Porém, a formação de valores sustentáveis não depende só da escola, mas de um conjunto de ações sociais, políticas, econômicas e ambientais em direção a uma sociedade mais justa, econômica e ecologicamente sustentável. Essa concepção combate as abordagens não integradoras que tendem a velar as dualidades e negar o caos. A educação ambiental não questiona apenas a degradação ambiental, mas a degradação social, avaliando quais são suas verdadeiras causas.

A questão do impacto ambiental do consumo foi definida, inicialmente, nos limites da noção de consumo verde, concentrando-se um pouco mais 
tarde no chamado consumo sustentável. Portilho (2005) explana que o consumidor verde foi amplamente definido como aquele que, além da variável qualidade/preço, inclui em seu "poder de escolha" a variável ambiental, preferindo produtos que não agridam ou aqueles denominados como não agressivos ao meio ambiente.

Raquel Traijber (2011) retrata sobre o cuidado com o planeta, que passa necessariamente pelo cuidado de cada um consigo mesmo, com os outros e com o meio em que vivemos. Cada ação individual pode provocar sérios impactos, positivos ou negativos sobre o funcionamento dessa engrenagem socioambiental, para isso, precisamos despertar a consciência e um senso de responsabilidade coletiva.

É importante, também, revisar nosso padrão de consumo com base na política dos cinco Rs: refletir, reduzir, recusar, reutilizar e reciclar. Segundo Borges (2011), significa questionar a lógica de produção e estimular ações de responsabilidades socioambientais empresariais e revolucionar os mecanismos de descarte, a fim de reduzir as marcas que deixamos no planeta.

Contudo, compreendemos que a maioria dos problemas ambientais é causada por processos desordenados, que comprometem a qualidade do meio ambiente, como o consumo desenfreado de produtos. Produtos que não sabemos de onde vem e como foram fabricados e, quanto à forma como os resíduos são descartados.

\section{Metodologia}

A natureza metodológica deste trabalho é qualitativa, por haver uma relação entre o mundo e o sujeito que não pode ser traduzida em números. Não necessitando de dados estatísticos para as análises dos resultados, por ser uma pesquisa exploratória e documental. Segundo Leite (2008) uma pesquisa descritiva relacionase com o processo de descrever fatos, fenômenos e dinâmicas sociais. Quando estudos desse tipo são investigados, o pesquisador não necessitará utilizar a estatística descritiva, ficando esta configurada como uma pesquisa qualitativa.

O presente trabalho foi realizado no Condomínio Recanto Verde, em Aracaju/SE, localizado no Bairro Farolândia. O condomínio possui 14 blo- cos, 224 apartamentos e 9 funcionários, incluindo todos da limpeza, portaria e encarregados.

Implantar coleta seletiva é uma tarefa que requer dedicação e empenho. Nesse sentido, foi elaborado um questionário direcionado aos condôminos e funcionários, o qual foi baseado no artigo de Gumiel e Neto (2009). Foram aplicados 19 questionários, cujas perguntas formadas foram adaptadas à linha de pesquisa apresentada nesse trabalho. Em seguida, analisa-se o local a ser depositado o lixo reciclado e debatido com o sindico a verba disponível para a compra dos materiais necessários.

Segundo Leite (2008), o questionário é a forma mais utilizada para coleta de dados, uma vez que possibilita analisar com melhor exatidão aquilo que se deseja. Assim, a abordagem no questionário em anexo direciona os respondentes para seu entendimento prévio de coleta seletiva, considerando os pontos: implantação da coleta seletiva, a quantidade de lixo gerado na residência e se o tipo de consumo influencia na quantidade elevada de lixo.

Outra ação de sensibilização foi a instalação no condomínio de plaquinhas orientando as pessoas quanto a essa problemática. Como por exemplo, "este ambiente é nosso, preserve-se que, lugar de lixo é no lixo". Essa estratégia também deve ser utilizada para a sensibilização do consumo e descarte dos resíduos como uma proposta ativa e constante. As frases de sensibilização ambiental devem ter a atuação ativa dos moradores do condomínio para uma ação que parte do individual para o coletivo.

\section{Resultados e Discussão}

O questionário foi aplicado com moradores e funcionários, no sentido de avaliar o entendimento prévio sobre coleta seletiva, sugestões de onde pode ser armazenado o resíduo reciclado, o que acham da inclusão obrigatória de coleta seletiva em condomínios, a quantidade de lixo produzido em suas residências e se o consumo desenfreado tem a ver com o aumento de lixo jogado fora.

Na primeira pergunta questionamos o que é coleta seletiva. Com base nessa colocação, foi analisado que todos têm conhecimento sobre coleta seletiva. Para os respondentes, coleta seletiva significa a 
separação dos resíduos que são aproveitados e os que não são, pois cada resíduo tem um tratamento próprio de reciclagem, caso o material orgânico venha a ser misturada com o inorgânico, a reciclagem do resíduo passa a ser inviável.

Na segunda pergunta foi questionado o que achavam da proposta de implantação da coleta seletiva no condomínio. Com base nos dezenove entrevistados, cinco disseram ser uma boa ideia; e quatorze responderam ser uma ideia excelente, com base na justificativa de que: "Seria muito bom para comunidade e para o meio ambiente. Vai da consciência de cada um"."Pode ter um maior cuidado com o destino dos resíduos, inclusive se tendo ganhos econômicos".

É importante ter um manuseio adequado em relação ao destino dos resíduos sólidos. De acordo com Oliveira (2009), quando coletados e tratados, inadequadamente, provocam efeitos diretos e indiretos na saúde da população e contribuem para degradação do ambiente. Atualmente, o processo de destinação dos resíduos sólidos domésticos é um problema de responsabilidade de âmbito individual, da comunidade e dos poderes públicos.

$\mathrm{Na}$ terceira pergunta analisamos as opiniões de cada um sobre onde poderíamos armazenar o resíduo reciclado no condomínio. Dos respondentes, cinco responderam não saber um local ideal para o armazenamento dos resíduos reciclados, pois não tem local para a devida separação e armazenamento no condomínio.

Os outros quatorzes respondentes pensaram haver um local para implantação de túneis apropriados, cada um com sua devida especificação (vidro, metal, papel, plástico) e separados dos resíduos orgânicos. Levando em consideração que esta separação teria que partir, primeiramente, das residências. Em seguida, depositados nos túneis do condomínio para o seu devido recolhimento e reciclagem.

A quarta pergunta refere-se à criação de uma Lei para implantação de coleta seletiva obrigatória em condomínios. Todos os dezenove respondentes acham uma excelente ideia a criação dessa lei, os quais levantaram alguns pontos como:realização de um estudo ambiental no local que serão armazenados os resíduos reciclados e a devida conscientização da comunidade local, gerando assim, melhorias para os moradores e percebendo que muitos resíduos jogados fora podem ser reaproveitados. "Além de que, estaríamos trabalhando para a renovação do meio ambiente". Explanaram também, a importância dessa lei não só em condomínios, mas em outros órgãos públicos ou privados de um modo geral.

$\mathrm{Na}$ quinta pergunta foi questionado se sabiam qual o destino do lixo em Aracaju/SE. Onze dos respondentes responderam que sim e, oito responderam que não. A responsabilidade de recolhimento do lixo é do município, em Aracaju/ SE a fiscalização é da Administração Estadual do Meio Ambiente - ADEMA.

Conforme informações do jornal O Globo, em Sergipe, desde o dia 16 de abril de 2013, o lixo recolhido na capital foi transferido do lixão do Bairro Santa Maria para o aterro sanitário particular em Rosário do Catete, pois causava muito acidente de aeronaves com as aves que sobrevoavam o lixão, além de haver trabalho infantil e moradia de famílias dentro do lixão.

Contudo, discutiram medidas mitigadoras para recuperar os danos causados pelo lixão, o plano de recuperação da área degradada e a inserção socioeconômica dos catadores de lixo. Portanto, percebe-se que apenas uma parte do processo foi solucionada e que ainda tem muito trabalho pela frente.

$\mathrm{Na}$ sexta pergunta indagamos se há o conhecimento de alguém ou algum condomínio que separa o lixo para coleta seletiva. Dez dos entrevistados informaram ter conhecimento e nove, não. Podemos ver essa questão como um complemento para futura implantação de coleta seletiva neste condomínio, em outros ou em moradias individuais, considerando que a maioria já havia visto a reciclagem em outros condomínios mesmo sendo individual ou mútua.

$\mathrm{Na}$ sétima pergunta, sobre o interesse em participar da implantação de uma coleta seletiva no condomínio, dezessete dos entrevistados informaram ter interesse para criar uma ambiente mais saudável, apenas dois responderam não haver interesse algum.

$\mathrm{Na}$ oitava pergunta, solicitamos respostas 
sobre a média da quantidade de lixo gerado semanalmente, medidos em sacos de lixo grandes. Dos entrevistados, oito responderam produzir um saco grande de lixo por semana, seis disseram gerar pouco menos de um saco e cinco mais de um saco grande. A quantidade de lixo gerado por dia pode-se perceber que é muito alta e, para que haja uma diminuição, é preciso impor limites em uma simples compra no supermercado, por exemplo.

A nona e última questão teve como base o excesso de lixo é causado pelas escolhas feitas na forma de consumo das pessoas. Quinze dos moradores pesquisados responderam sim e levantaram pontos interessantes como: consumir muitos produtos industrializados, gerando uma maior quantidade de embalagens ou materiais a serem descartados.

Outro destaque, foi se cada morador se responsabilizasse em fazer a separação do seu lixo, resolveria grande parte da situação, evitando o desperdício e obtendo uma maior consciência sobre o cuidado com o meio em que vivemos. Foi citada também pelos entrevistados, a falta de compromisso para uma melhor escolha dos produtos, os quais boa parte deles é de difícil decomposição, o que ocorre por uma falta de Educação Ambiental da comunidade.

Dos respondentes, apenas uma pessoa disse que o consumo não é um problema para o excesso de lixo, justificando que a quantidade de material consumido depende muito da necessidade de cada residência. Com base nesta resposta, percebe-se que o mesmo não entende ser a nossa forma de consumo um problema a mais para o excesso de resíduos que geramos no nosso dia a dia.

"Contudo, o consumo é um mal necessário para nossa sobrevivência, à possibilidade de uma mudança neste sentido, é um tanto quanto complicada, mas não impossível de resolver. Para isso, precisaríamos enfrentar o grande desafio de influenciar e modificar o pensamento das pessoas, pois com base nas respostas dos condôminos e funcionários, percebe-se que os mesmos entendem o que está errado e algumas formas de solucionar ou melhorar este problema".

Um dos pontos desfavoráveis identificados foi a falta momentânea de recursos financeiros do condomínio para a construção de um espaço de deposito do lixo reciclado até a cooperativa recolher, inviabilizando a implantação da coleta seletiva após a realização da pesquisa, apesar do interesse dos moradores pesquisados.

\section{Considerações Finais}

Essa proposta de implantação da coleta seletiva em um condomínio de Aracaju/SE, localizado em área urbanizada, é, antes de qualquer coisa, uma das maneiras de refletir sobre uma conscientização ambiental, a qual somente será amenizada através da educação ambiental. Estes procedimentos iniciais e a realização da coleta seletiva de maneira periódica e contínua, torna os participantes ativos e responsáveis pela motivação da comunidade na continuidade das ações.

Contudo, observamos que o lixo domiciliar é um dos problemas causados pelo próprio individuo impulsionado através da cultura do consumo. Para o enfrentamento desse problema é preciso, além de uma nova postura em relação ao consumo, a educação ambiental para que haja uma convivência harmoniosa entre ambiente e sociedade.

\section{Referências}

ARACAJU. PREFEITURA MUNICIPAL DE.Emsurb desenvolve o serviço de coleta seletiva na capital.Seminário Nacional de Logística Reversa. Disponível em: <http://www.rio.rj.gov. br/dlstatic/10112/6552138/4177416/SecretariaMunicipaldoMeioAmbientedeAracajuEduardoLimaSecretarioMunicipaldeMeioAmbientedeAracaju.pdf $>$. Acesso em 22.03.2016.

BRASIL.Lei $n^{\circ}$ 9795, de 27 de abril de 1999. Institui a Política Nacional de Educação Ambiental. Disponível em: $<$ http://www.planalto.gov. br/ccivil_03/leis/L9795.htm>. Acesso em: 15 de agosto de 2016.

BORGES, Carla. Espaços Educadores Sustentáveis.In: Tv Escola: o canal da educação. Espaços Educadores Sustentáveis. Salto para o Futuro. Ano XXI, Boletim 07 - Junho 2011. Disponível em: <http://www.nuredam.com.br/files/ 
documentos_mec/194055espacoseducadoressustentaveis.pdf $>$. Acessado em: 03/08/2016.

COSTA, Silvia de Souza. Lixo Mínimo: Uma Proposta Ecológica para Hotelaria. Rio de Janeiro: SENAC Nacional, 2007.

DIÁRIO DE COIMBRA. Planeta Terra: a nossa casa comum. 27 de julho de 2015. Disponível: $<$ https://www.ulisboa.pt/wp-content/uploads/ 21jul_planeta_terra_ISA.pdf $>$ Acesso em 5 de junho de 2018.

FERREIRA, Aurélio Buarque de Holanda. Novo Dicionário Aurélio da Língua Portuguesa. Rio de Janeiro, $2^{\text {a }}$. ed. Rio de Janeiro: Nova Fronteira, $1986.1838 \mathrm{p}$.

GRIMBERG, Elisabeth. A Política Nacional de Resíduos Sólidos:a responsabilidade das empresas e a inclusão social. Instituto Pólis. Publicado em: 22/07/2004. Disponível em: <http://www. polis.org.br/uploads/1177/1177.pdf $>$ Acessoem: 17 de agosto de 2016.

GUMIEL, F. e NETO, J. L. S. Estudo e Implantação de Sistema de Coleta Seletiva e Reciclagem em Habitações Coletivas: Estudo de Caso no Condomínio Solar Tocantins. Portal Católica Projetos de Gestão Ambiental, 2009. Disponível em: $\quad<$ http://www.catolica-to.edu.br/portal/portal/downloads/docs_gestaoambiental/projetos 2009-2/4periodo/Estudo_e_implantacao_de_ sistema_de_coleta_seletiva_e_reciclageme $\mathrm{m}_{-}$ habitacoes_coletivas_estudo_de_caso_no_condominio_solar_tocantins.pdf $>$ Acessoem: $16 \mathrm{de}$ agosto de $201 \overline{6}$.

JORNAL G1. Saiba como funcionará o descarte de lixo com fechamento de lixões em SE. TV Sergipe. Disponível em: <http://g1.globo.com/ se/sergipe/noticia/2013/04/saiba-como-funcionara-o-descarte-de-lixo-com-fechamento-de-lixoes-em-se.html $>$ Acessado em: 25 de agosto de 2016.

LEITE, F. T.Metodologia Científica: métodos e técnicas de pesquisa. Monografias, dissertações, teses e livros. $3^{\mathrm{a}}$ edição, Aparecida, SP: Ideias \& Letras, 2008.

SERGIPE. MINISTÉRIO PÚBLICO DO ESTADO DE. Promotores em estágio probatório visitam cooperativas de reciclagem de Aracaju. 29 de agosto de 2016. Disponível:<http://www. mpse.mp.br/corregdoria2008/NoticiaExibis.aspx?id $=744$

4>Acesso em : 29 de agosto de 2016.

NEPOMUCENO, A. L. O; CARVALHO, M. E. S.; REZENDE, V. A. Educação ambiental e aspectos socioambientais. Centro de educação superior à distância, UFS. São Cristóvão, 2014.

OLIVEIRA, A. C. M.; MAZZARINO, J. M.; TURATTI, L. A responsabilidade na destinação dos resíduos sólidos domésticos: análise de discursodos cidadãos no município deLajeado. X Salão de Iniciação Científica- PUCRS, 2009.

PORTILHO, F. Consumo Sustentável: limites e possibilidades de ambientalização e politização das práticas de consumo. Cad. EBAPE.BR [online]. 2005, vol.3, n.3, pp.01-12. ISSN 1679-3951. Disponível em: $<$ http://www.scielo.br/scielo.php ?pid=S1679-39512005000300005\&script $=$ sci_ abstract\&tlng=pt $>$. Acesso em 20.03.2016.

SILVA, D. G. A Importância da educação Ambiental para a Sustentabilidade. Faculdade Estadual de Educação. Ciências e Letras de Paranavaí. São Joaquim: 2012.

THIOLLENT, M. "Notas para o debate sobre a Pesquisa-Ação". In: Brandão, C. R. Repensando a Pesquisa Participante. São Paulo: Brasiliense, 1998.

TRAJBER, R. Vida sustentável: ações individuais e coletivas. In: Tv Escola: o canal da educação. Espaços Educadores Sustentáveis. Salto para o Futuro. Ano XXI, Boletim 07 - Junho 2011. Disponível em: <http://www.nuredam.com.br/files/ documentos_mec/194055espacoseducadoressustentaveis.pdf $>$. Acessado em: 03/08/2016. 
TRISTÃO, M. Saberes e fazeres da educação ambiental no cotidiano escolar. In: Revista brasileira de educação ambiental. Rede Brasileira de Educação Ambiental.- $\mathrm{n}^{\circ}$ 0, nov. 2004. - Brasília: Rede Brasileira de Educação Ambiental, 2004.

VILHENA, A.; D'ALMEIDA, M.L.O. Segregação de materiaisIn: D'ALMEIDA, M.L.O.; VILHENA, A. (Coord.). Lixo Municipal: manual de gerenciamento integrado. $2^{\mathrm{a}}$ ed. São Paulo: Instituto de Pesquisas Tecnológicas - IPT/Compromisso Empresarial para Reciclagem - CEMPRE, 2000.

\section{Sobre os autores}

Mayane Menezes Santos, Licenciada em Ciências Biológicas pela UFS. Especialista em Educação Ambiental com Ênfase em Espaços Educadores Sustentáveis pela UFS.mayanemenzes@ hotmail.com

Ângelo Francklin Pitanga, Licenciado e Mestre em Química pela UFS, Doutor em Educação pela UFS. Professor EBTT do IFBA, campus Paulo Afonso,BA. afpitanga2@gmail.com 